
REVISTA ARA Nº 3 . PrimAVERA+VERÃO, 2017 • GRUPO MUSEU/PATRIMÔNIO FAU-USP

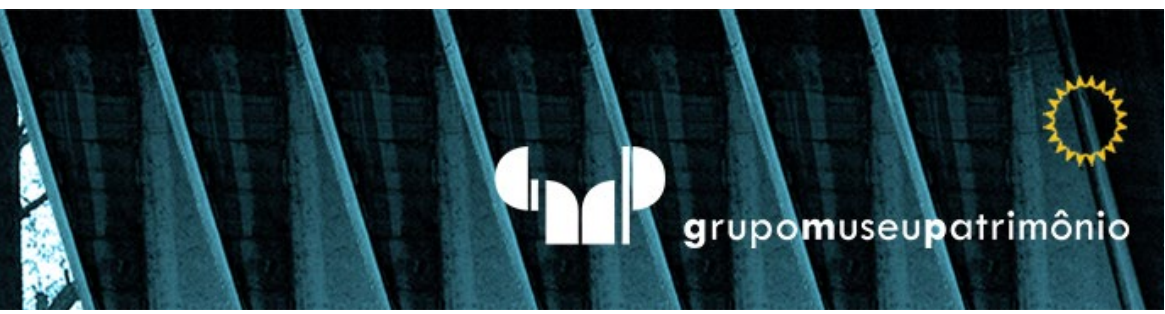

Cidade: entre experiência e imagem

\section{City: between experience and image}

Thiago Rocha Ribeiro

Arquiteto e urbanista, FAUUSP, São Paulo, Brasil. rocha.ribeiro.thiago@gmail.com 


\title{
Resumo
}

O ensaio constitui-se na criação de imagens a partir de fotografias e utilizando o caminhar pela cidade como procedimento de pesquisa. Particularmente se voltou para captar e explorar o conceito de Atmosferas encontrado nos textos de Peter Zumthor. Formadas por uma trama de camadas (sons, cheiros, vivências, tempos, escalas etc.) elas são subjetivas, efêmeras, de conexão imediata e principalmente protagonistas sobre a dinâmica perceptiva estabelecida entre o espaço e o sujeito. A decodificação destas experiências em discurso visual e o cruzamento com os filmes Blow-up, Her e os textos de Susan Sontag permitiu ainda estruturar uma discussão sobre questões relativas à própria construção de imagens e a nossa relação com elas.

Palavras-Chave: cidade, imagem, experiência, fotografia e representação.

\begin{abstract}
The work is based on image creations from photography using the walk through town as a research procedure, particularly focused to capture and explore the concept of Atmospheres found in Peter Zumthor's texts. Created by a combination of layers (sounds, odors, experiences, times, scales) those images are subjective, ephemeral, of immediate connection and the mainly protagonists on the perceptual dynamics established between space and the subject. Decoding these experiences into visual speech and relating it with the films Blow Up, Her and Susan Sontag's texts, allowed structuring a discussion on the image construction itself.
\end{abstract}

Keywords: city, image, experience, photography and representation. 
O filme Blow-up (1966), do cineasta italiano Michelangelo Antonioni, teve o seu roteiro inspirado no conto Las babas del diablo, publicado originalmente na Argentina em 1959, pelo autor Júlio Cortázar. O enredo traz como protagonista um aparentemente famoso fotógrafo de moda, Thomas (David Hemmings), que trabalha na cidade de Londres dos anos de 1960.

Logo nas cenas iniciais entendemos que ele se relaciona com o mundo de uma maneira apática, automatizada e mesmo tendo um certo sucesso profissional não parece satisfeito com as suas atividades. Entretanto, ainda no começo do filme, essa mecanicidade é interrompida por uma sessão fotográfica, na qual Thomas e a modelo estabelecem uma dinâmica bastante significativa da relação entre fotografia, mundo e representação.

Nessa sequência antológica, Thomas, após tirar as primeiras fotos usando uma câmera grande formato e estática, bebe um copo de vinho e passa a utilizar uma câmera $35 \mathrm{~mm}$ com lente $50 \mathrm{~mm}$, a que mais se aproxima do campo de visão dos olhos humanos. A partir disso a distância entre fotógrafo e modelo vai diminuindo até que a modelo deita-se pelo chão, exibindo-se, e o protagonista a acompanha, beijando-a no pescoço, estimulando-a e fotografando-a.

Até que os dois em uma posição claramente sexual iniciam uma série de movimentos que culminam em gritos extasiados de Thomas que aparentemente conseguira as fotos que desejava com a sessão. Logo em seguida a este gozo, o protagonista retorna à sua frieza mecânica, deixando a modelo ali no chão. Esta cena sexualizada nos mostra que o protagonista tem momentos de extrema excitação e fascínio quando mediados por um aparato mecânico.

Hoje em dia, é comum que pessoas insistam em lembrarse do acidente violento do qual foram vítimas - um desastre de avião, um tiroteio, uma bomba terrorista - e que 'parecia um filme'. Assim nos expressamos, sendo aparentemente desnecessárias quaisquer outras descrições, quando queremos explicar como tudo era tão real (SONTAG, 1986, 155) 
Além de Blow-up e da afirmação de Susan Sontag, pode-se olhar para o filme Ela (HER, título original, 2013) do diretor Spike Jonze. A trama, encenada em um futuro próximo, narra a história de Theodore (Joaquin Phoenix), um escritor solitário que compra um novo software, desenhado para ser um "amigo" e assistente pessoal com dedicação em tempo integral. O sistema, dotado de inteligência artificial, se auto nomeia Samantha. E se comunica com o protagonista por meio de uma voz interpretada pela atriz Scarlett Johansson. Com o desenrolar da narrativa, Theodore passa a desenvolver uma relação afetivo-amorosa com Samantha.

Estes três exemplos escolhidos elaboram a problemática capacidade das representações ultrapassarem a simples mímese da realidade, desta forma, pode haver: um romance entre um ser humano e uma voz sem corpo; podemos descrever e qualificar a vivência real utilizando uma narrativa ficcional como parâmetro; ou ainda, conseguimos desfrutar e dos prazeres sexuais enquanto estamos olhando por um mecanismo de apreensão da realidade. Há uma valorização da imagem sobre o mundo real: uma supervalorização dos estímulos virtuais sobre os reais.

Retornando ao contexto de Blow-up, quando Thomas sai por Londres na tentativa de concluir o seu trabalho autoral e acaba em um parque onde se depara com um casal. Tentando manter-se escondido por trás das árvores, ele inicia uma série de disparos enquadrando aquela cena corriqueira. Entretanto, ao dar-se por satisfeito, a mulher do casal percebe a sua presença e começa a persegui-lo, exigindo o filme da máquina. Como o protagonista não se dispõe a Ihe entregar os negativos, ela sai correndo e desaparece.

Michelangelo Antonioni, neste momento, fixa o nosso olhar por mais um tempo para aquele parque vazio ao som dos ruídos do vento balançando as árvores. Esta imagem final, pacata e banal será o terreno de uma série de descobertas e movimentos, dos quais nem Thomas ainda percebeu ter sido testemunha. 
A mulher do parque reaparece, agora no estúdio do protagonista, e novamente tenta conseguir o rolo com as fotos. Para despistá-la, Thomas faz uma troca e lhe entrega um rolo virgem. A excessiva preocupação da mulher torna-se um indício de haver algo suspeito naquela aparente cena no parque. O fotógrafo decide revelar as fotos e iniciar uma sequência investigativa, na qual passa a examiná-las através de lupas e ampliações sucessivas, o que no jargão fotográfico é conhecido como blow-up.

Estes aumentos excessivos acabam alterando a nitidez dando lugar a uma série de manchas e ruídos. Em meio a este amálgama, atrás de um arbusto existe algo, uma mão, uma mão empunhando uma arma e uma mancha em outra posição que lembra um corpo. Thomas, então, passa a acreditar que naquela tranquila cena havia acontecido um assassinato. Todavia, os indícios deste crime estão fundamentados em imagens quase abstratas e que ganharam sentido graças ao olhar de Thomas que procurava vorazmente por algo.

As demais cenas do filme fomentam uma trama que torna bastante complexa a resolução deste suposto crime. Focando, principalmente, no protagonista e sua ineficiente busca por respostas. Sendo assim, antes e mais importante que a existência ou não do crime, há a independência da câmera, sobre a vivência do fotógrafo, o aparato que captou algo cujos olhos humanos falharam em perceber.

Blow-up é uma expressão e significa ampliar sucessivamente. Entretanto, Michelangelo Antonioni nos apresenta uma narrativa na qual esse aumento excessivo, essa explosão do grão fotográfico, que ao se expandir torna-se ruído, corresponde também à perda de significado, ou melhor, destrói-se a nitidez e as referências iniciais, e, com isso, constroem-se novos significados, ou até uma nova realidade. $\mathrm{O}$ homicídio retratado no filme só pode ser real por ser, e enquanto for, imagem.

A narrativa apresenta, novamente, uma renovação sobre a maneira como olhamos o mundo e o embate entre o que é real e o que é representação. 0 crime existe para o protagonista e para nós espectadores por meio dos produtos de um complexo processo fotográfico. Assim sendo, a fotografia se 
mostra não mais como uma simples cópia mecânica e verossímil do real, mas como é uma ação agitada, fendida que a partir de um enquadramento subjetivo da realidade propõe novas possibilidades de significação e leituras.

As imagens apresentadas neste ensaio são resultados de experiências e derivas urbanas realizadas em 2016 para o Trabalho Final de Graduação em Arquitetura na FAU-USP. Elas procuram destacar a cidade não apenas como paisagem, mas explorar e materializar a experiência do sujeito no espaço.

Dialogando com Peter Zumthor e Georges Didi-Huberman formulou-se que as experiências perceptivas na cidade são protagonizadas por uma dinâmica na qual o sujeito e o espaço posicionam-se como pólos dialéticos. Nesta dinâmica o olhar atravessa uma trama de camadas (sons, cheiros, vivências, tempos, escalas etc.) e obtém o que aqui, com base em Zumthor, convencionou-se chamar de Atmosferas.

Elas são efêmeras, de conexões imediatas e subjetivas. Amalgamadas com o conceito de instante, que pode ser compreendido como uma ruptura temporal, um disparo que rompe momentaneamente o fluxo do cotidiano. A fotografia apreende este rompimento, torna-o output de um aparelho, desloca-o e Ihe atribui novos significados, desta maneira, o ato de fotografar nos permite recriar e reconfigurar frações do visível.

As fotos do ensaio se abrem em sua intrínseca pluralidade. São registros de uma presença naqueles lugares mas também são narrativas visuais que procuram reimaginar aqueles espaços trabalhando sobre a noção de mudanças atmosféricas, interação de inúmeras camadas e adensamento de tempos visíveis.

São imagens constituídas por vibrações, ruídos incômodos, transparências, linhas, rastros compactados uns sobre os outros, produzidos por elementos conhecidos: a fotografia, a cidade, os espaços e os sujeitos, entretanto manipulados e reordenados, o que possibilita assim como em Blow-up, encontrar novas possibilidades e significações. Esta insubordinação contra a mímese, a aparente 
verossimilhança intrínseca à fotografia dialoga com um possível questionamento crítico da nossa realidade mediada por construções imagéticas.

Vídeos, fotos, emojis, feeds, snapchats, instagram, facebook, youtube são cada vez mais protagonistas e imperativos na construção dos significados das coisas e consequentemente ao que somos. Isto acaba tornando-as mais reais que a própria realidade, o real é cada vez mais aquilo que as câmeras mostram. 


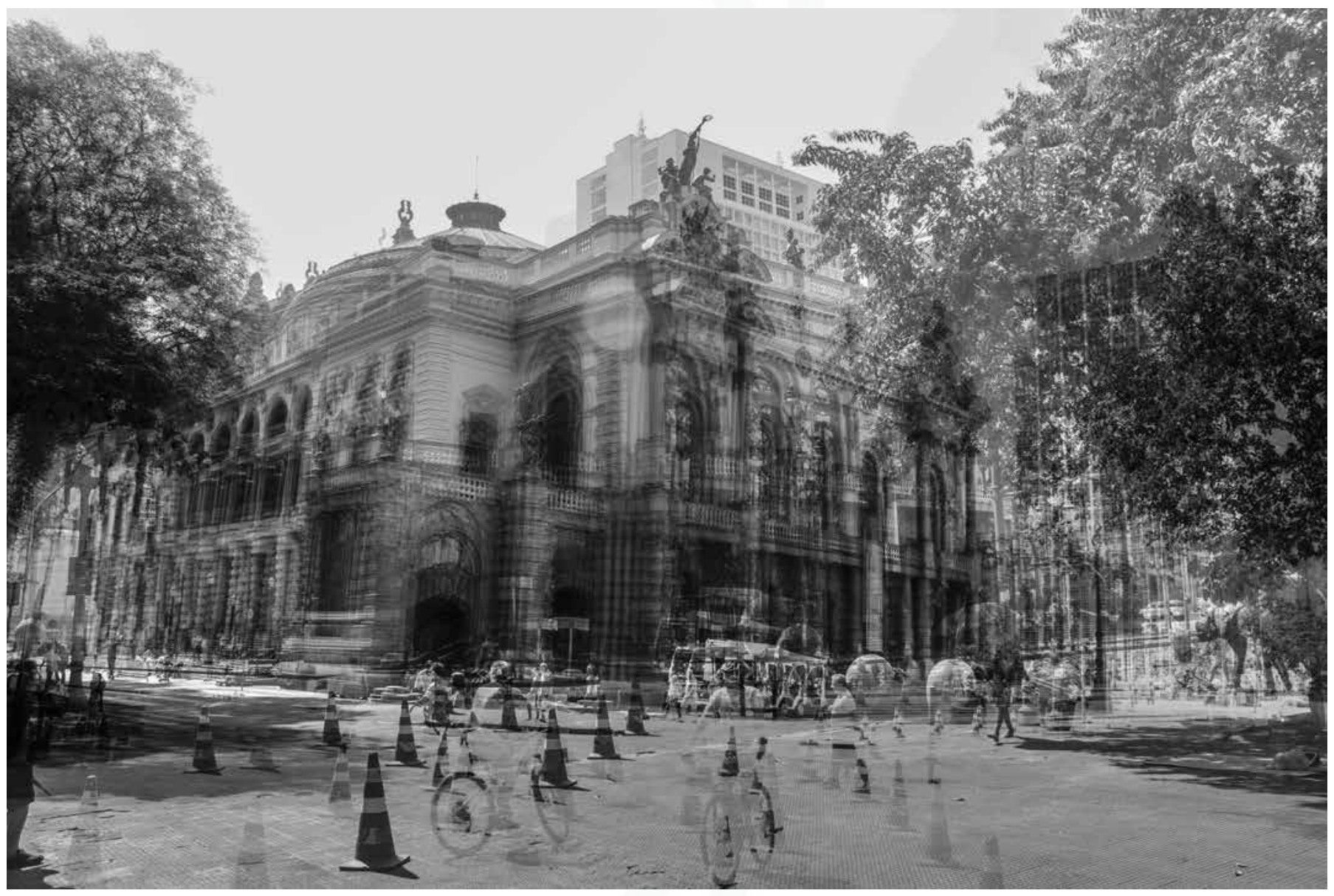




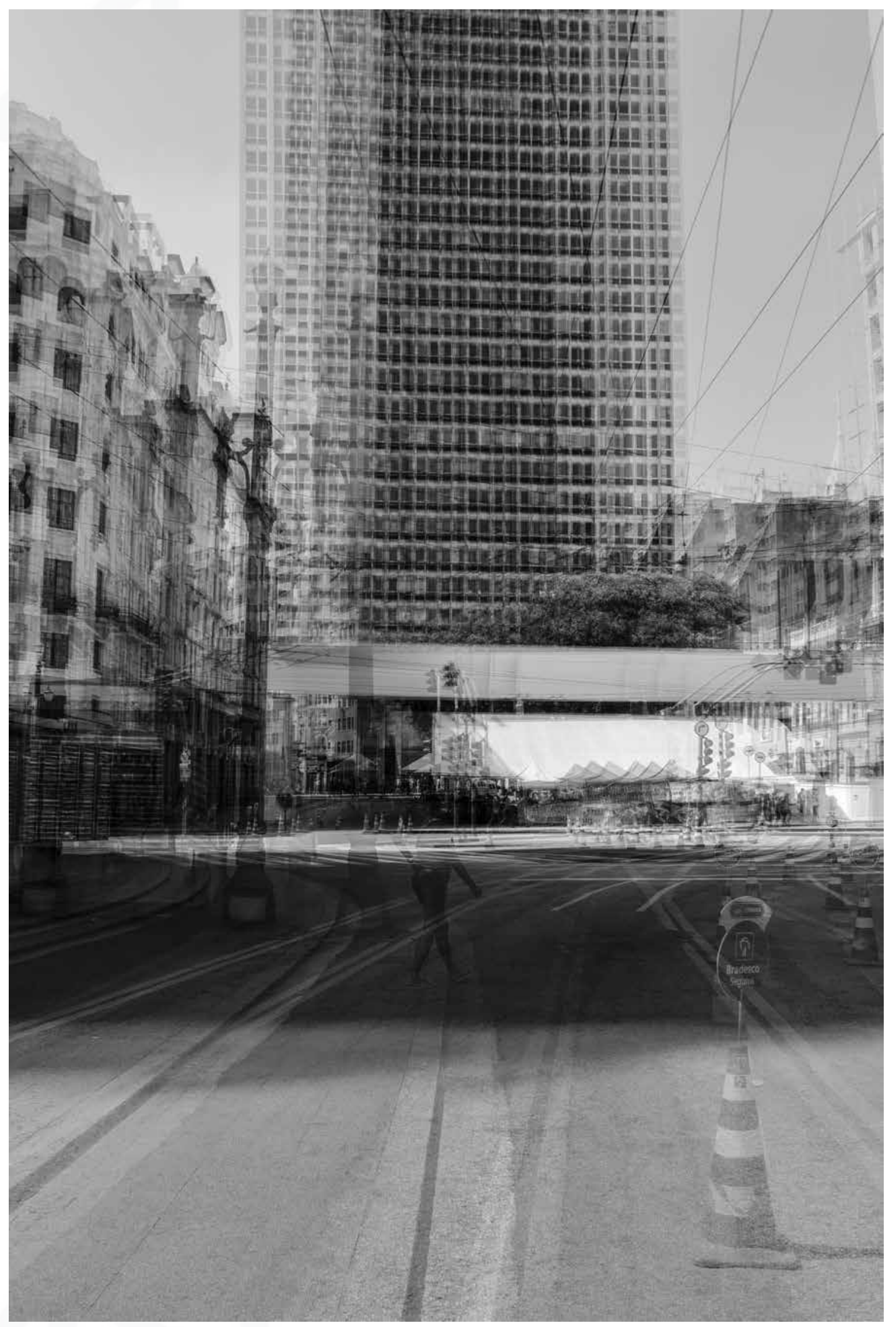




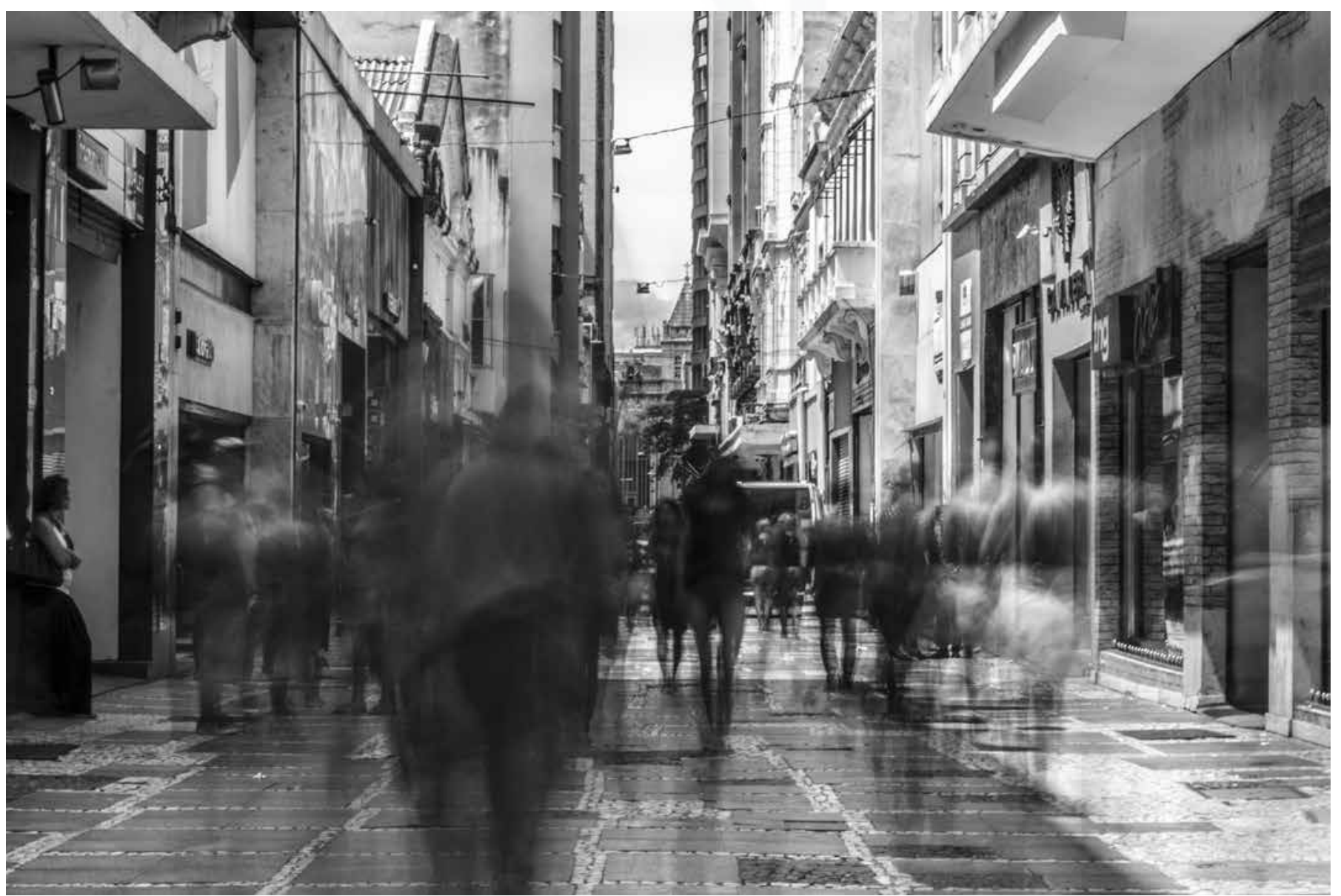




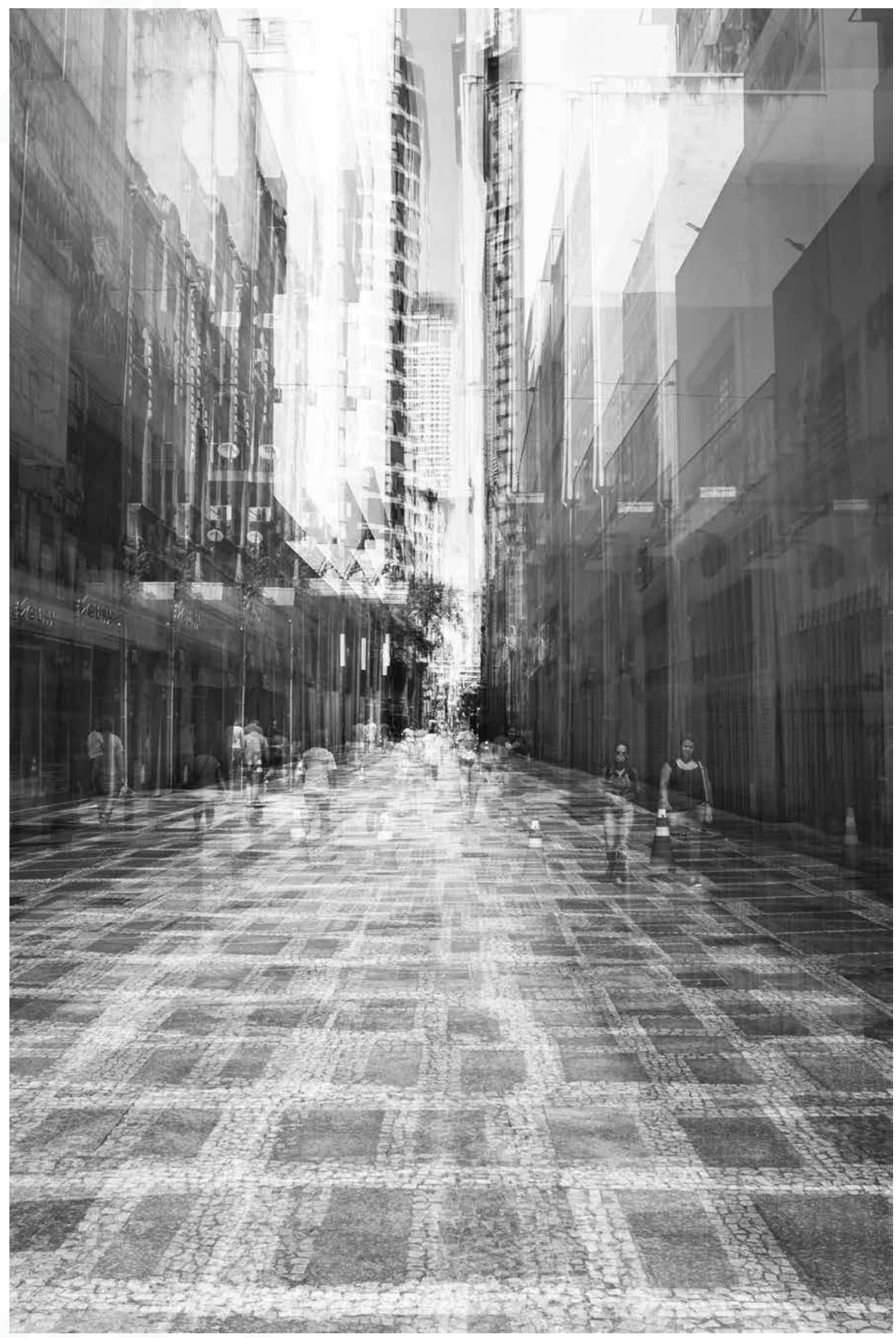




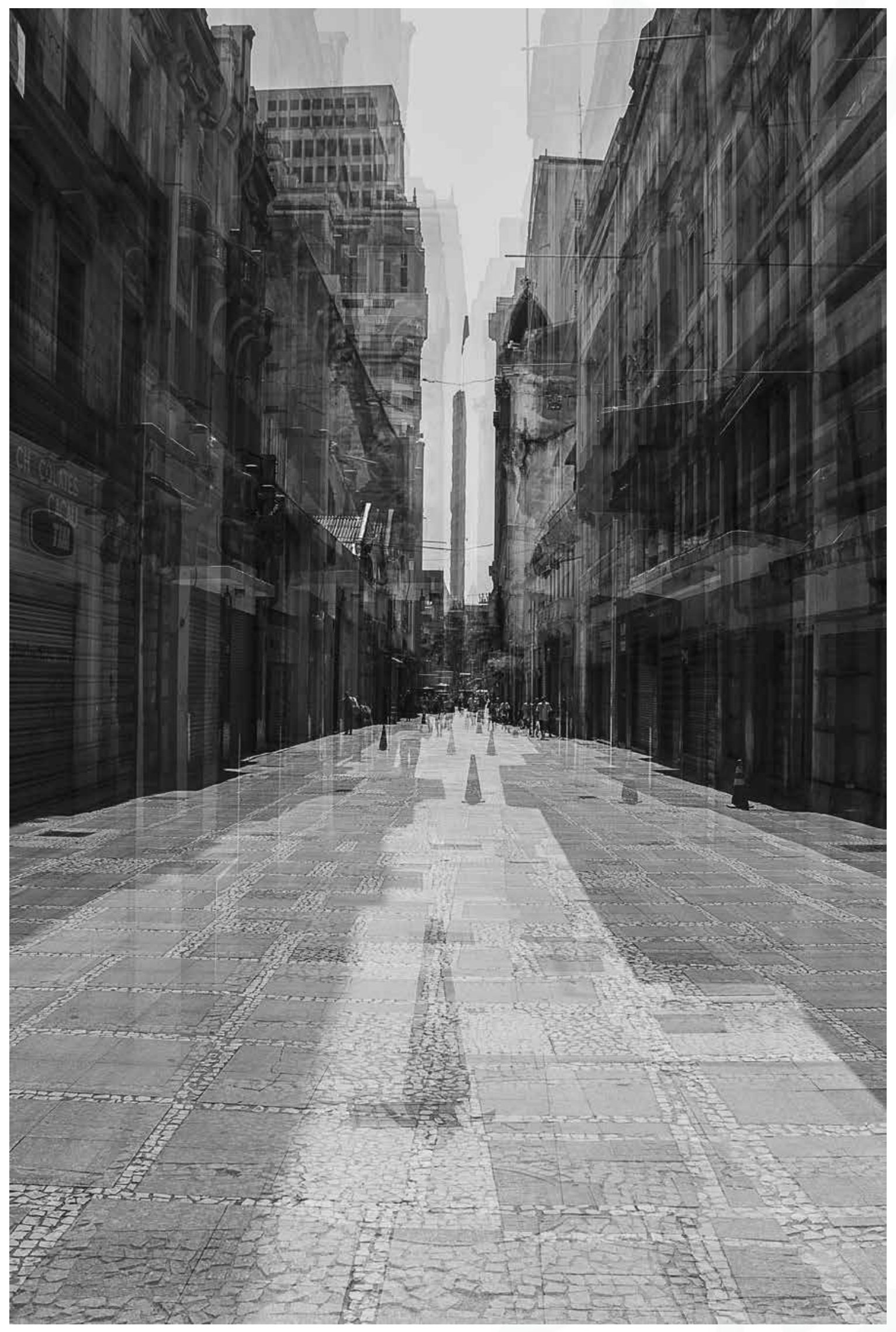




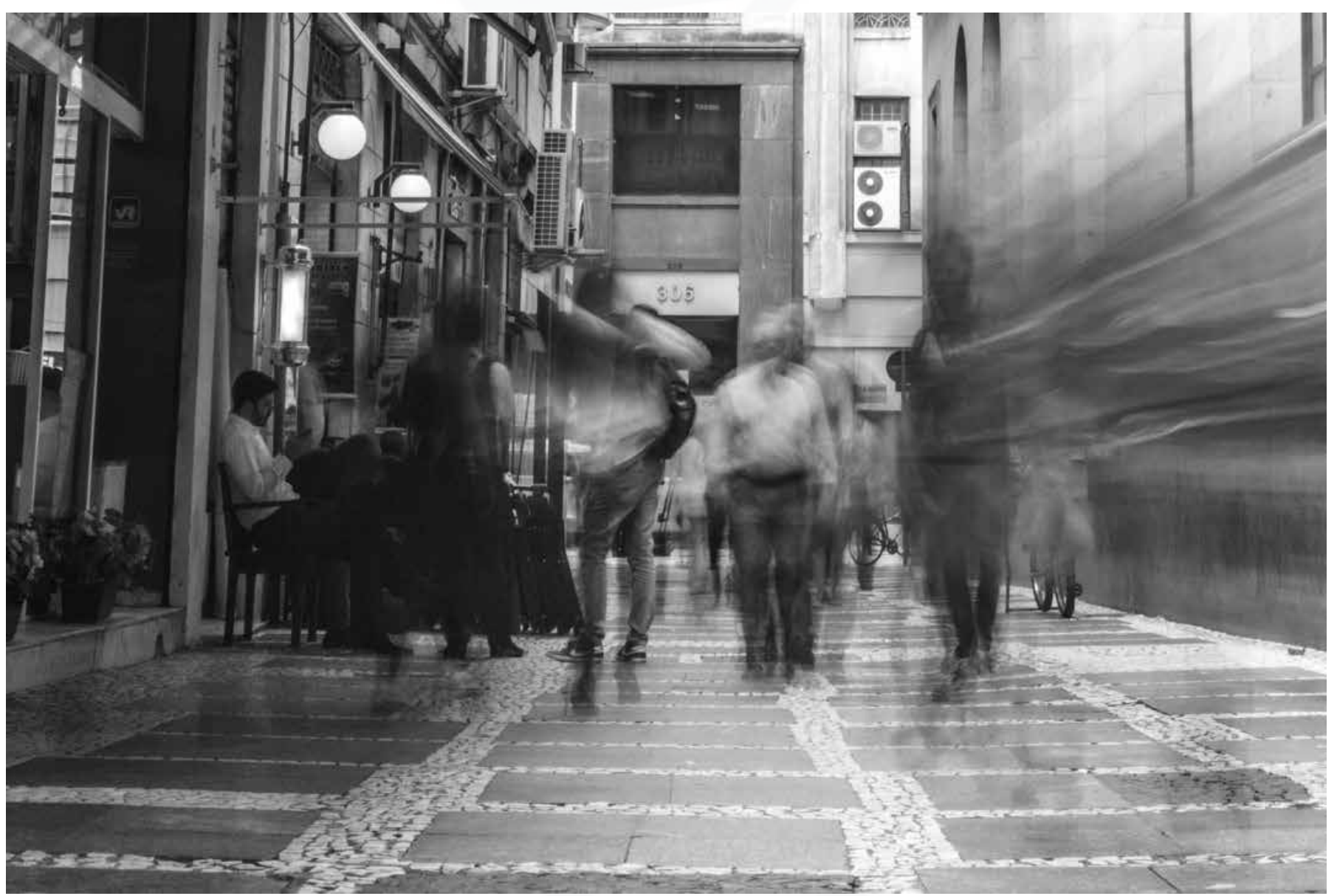




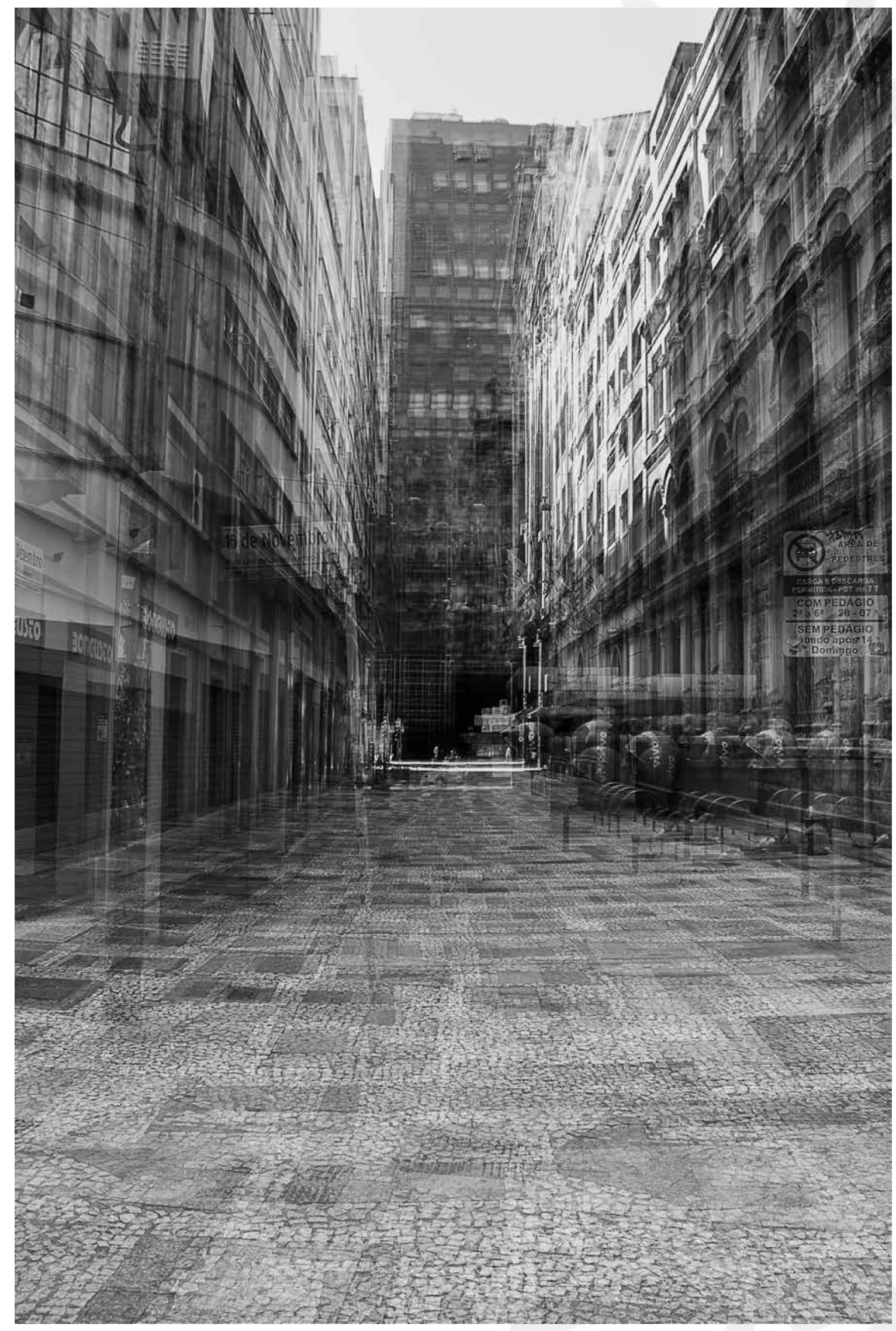




\section{REFERÊNCIAS}

Livros

BENJAMIN, Walter: Pequena História da Fotografia In: Obras Escolhidas, vol. 1. São Paulo: Brasiliense, 1994.

CANETTI, Elias. Vozes de Marrakesh (Die Stimmen Von Marrakech, tradução Marijane Lisboa). Porto Alegre: L\&PM, 1987.

DIDI-HUBERMAN, Georges. O que vemos, o que nos olha. São Paulo: Editora 34, 2010.

CARERI, Francesco. Walkscapes. O caminhar como prática estética. Barcelona: Gustavo Gili, 2015.

SONTAG, Susan. Ensaios sobre Fotografia. Lisboa: Publicações Don Quixote, 1986.

ZUMTHOR, Peter. Atmosferas. Barcelona: Gustavo Gili, 2006.

Pensar a arquitectura. Barcelona: Gustavo Gili, 2005.

\section{Filmes}

BLOW-UP. Direção: Michelangelo Antonioni, Produção: Carlo Ponti. Reino Unido: Metro Goldwin Mayer, 1966, 1 DVD

HER. Direção: Spike Jonze, Produção: Megan Ellison, Spike Jonze e Vincent Landay. Estados unidos: Warner Bros. Pictures, 2013, 1 DVD 